\title{
Common mental disorders in Petrópolis-RJ: a challenge to integrate mental health into primary care strategies
}

\section{Transtornos mentais comuns em Petrópolis-RJ: um desafio para a integração da saúde mental com a estratégia de saúde da família}

\author{
Sandra Fortes, ${ }^{1}$ Claudia S. Lopes, ${ }^{2}$ Luiz A. B. Villano, ${ }^{1}$ Mônica R. Campos, ${ }^{3}$ Daniel A. Gonçalves, ${ }^{4}$ \\ Jair de Jesus Mari ${ }^{5}$ \\ 1 School of Medical Science, Universidade do Estado do Rio de Janeiro (UERJ), Rio de Janeiro, RJ, Brazil \\ ${ }^{2}$ Institute of Social Medicine, Universidade do Estado do Rio de Janeiro (UERJ), Rio de Janeiro, RJ, Brazil \\ ${ }^{3}$ Public Health National School, Rio de Janeiro, RJ, Brazil \\ ${ }^{4}$ Escola Paulista de Medicina (EPM), Universidade Federal de São Paulo (UNIFESP), São Paulo, SP, Brazil \\ ${ }^{5}$ Centre for Public Mental Health, Health Services and Population Research Department, Institute of Psychiatry, King's College, University of \\ London, London, UK
}

\begin{abstract}
Objective: Common mental disorders are present in more than $50 \%$ of patients attending primary care clinics. The main objectives of this study were to detect whether there is any special group of patients within the Family Health Strategy that should be considered to be in greater risk for common mental disorders and to recommend alternative interventions to aid these patients. Method: In 2002, a cross-sectional study on common mental disorders seen at Family Health Strategy centers was conducted in Petrópolis, State of Rio de Janeiro. Results: Common mental disorders were associated with women $(\mathrm{OR}=2.90 ; 95 \% \mathrm{CI} 1.82-4.32)$, younger than 45 years of age $(\mathrm{OR}=1.43 ; 95 \%$ CI $1.02-2.01)$, with a monthly per capita family income of less than US $\$ 40.00(\mathrm{OR}=1.68 ; 95 \% \mathrm{CI}$ 1.20-2.39), and without a partner $(\mathrm{OR}=1.71 ; 95 \%$ CI 1.22-2.39). Illiteracy was associated with common mental disorders among patients who were not extremely poor. Social support networks such as going often to church $(\mathrm{OR}=0.62 ; 95 \% \mathrm{CI} 0.43-0.89)$; participating in artistic and sporting activities $(\mathrm{OR}=0.42 ; 95 \% \mathrm{CI} 0.26-0.70)$ and having at least four trusted relatives or friends $(\mathrm{OR}=0.53 ; 95 \% \mathrm{CI} 0.31-0.91)$ was inversely associated with common mental disorders. Discussion: Poor women with little social support represent a special group at risk for common mental disorders in the primary care setting. Some countries have developed special interventions to treat patients with common mental disorders in primary care. Conclusion: Mental health care programs could include evidence-based psychosocial interventions to assist women in overcoming the vicious circle of poverty and dealing with their mental disorders.
\end{abstract}

Descriptors: Mental disorders; Primary health care; Mental health; Gender identity; Strategies

\section{Resumo}

Objetivo: Transtornos mentais comuns estão presentes em cerca de 50\% dos pacientes atendidos nas unidades de atençāo primária. Os principais objetivos deste estudo foram investigar a presença de grupos especiais de pacientes na Estratégia de Saúde da Família que devam ser considerados como em maior risco para transtornos mentais comuns e recomendar intervençôes alternativas que auxiliem estes pacientes. Método: Em 2002, um estudo de corte transversal sobre transtornos mentais comuns foi realizado nas unidades do Programa de Saúde da Família em Petrópolis-RJ. Resultados: A presença de transtornos mentais comuns estava associada a ser mulher $(O R=2,90 ; 95 \% C I 1,82-4,32)$, ter menos de 45 anos $(O R=1,43 ; 95 \%$ CI 1,02-2,01), com uma renda per capita familiar menor que U\$40,00 $(O R=1,68 ; 95 \%$ CI 1,20-2,39) e sem companheiro $(O R=1,71 ; 95 \% C I$ 1,22-2,39). Analfabetismo se associava a transtornos mentais comuns em pacientes que não eram extremamente pobres. Redes de suporte social, tais como frequentar regularmente a igreja $(O R=0,62 ; 95 \% C I$ 0,43-0,89), participar de atividades esportivas e artísticas $(O R=0,42 ; 95 \%$ CI 0,26$0,70)$ e ter pelo menos quatro amigos ou parentes em quem se podia confiar $(O R=0,53 ; 95 \%$ CI 0,31-0,91) estavam inversamente associadas a ter transtornos mentais comuns. Discussão: Existe um grupo de risco especial para transtornos mentais comuns na atenção primária: mulheres, pobres, com pouco suporte social. Intervençôes especiais para que sejam cuidadas na atenção primária têm sido desenvolvidas em outros países. Conclusão: Intervençôes terapêuticas com comprovada evidência cientifica para apoiar essas mulheres a romper o círculo vicioso de pobreza e transtornos mentais podem ser inseridas nas açôes de saúde mental.

Descritores: Transtornos mentais; Atenção primária à saúde; Saúde mental; Identidade de gênero; Estratégias

\section{Introduction}

Since the 1980s, following the studies carried out by Goldberg et al., ${ }^{1}$ the high prevalence of mental disorders among patients attending general health care centers, especially in primary care, became well known. The mean prevalence of mental disorders at

\section{Correspondence}

Sandra Fortes

UDA Mental Health and Medical Psychology; School of Medical Sciences Hospital Universitário Pedro Ernesto/Universidade do Estado do Rio de Janeiro Boulevard Vinte e Oito de Setembro, $77-4^{\circ}$ andar - Vila Isabel 20550-030 Rio de Janeiro, RJ, Brasil

Phone/Fax: (+55 21) 2587-6469
Submitted: April 5, 2010

Accepted: August 16, 2010 
the 15 general health care centers surveyed by the World Health Organization Study on Psychological Problems in General Health Care (WHO/PPGHC) ${ }^{2}$ was around 23\%, although it reached 38\% in Rio de Janeiro ${ }^{2}$ and 50\% in Santiago de Chile. ${ }^{2}$ Studies conducted by Mari, Busnello and Iacopponi in traditional primary care centers in Brazil during the 1980s showed that approximately $50 \%$ of patients attending these centers presented common mental disorders (CMD). ${ }^{3-5}$ The results from a study conducted in Petrópolis in the State of Rio de Janeiro in 2004, ${ }^{6}$ demonstrated a prevalence of $56 \%$ of CMD at the centers of the Family Health Program (FHP). In addition, studies conducted in communities covered by FHP teams in different parts of Brazil found a CMD prevalence ranging from $21.7 \%$ to $35 \%$, depending on the region..$^{7,8}$

CMD patients present depression and anxiety and a large number of these patients will be considered subliminal cases by traditional diagnostic criteria. ${ }^{9}$ This is so because these patients have unspecific symptoms, followed by general complaints such as worries and irritability, and the decisive presence of somatic medically unexplained symptoms. This form of presenting mental suffering is cultural, and is particularly frequent among Latin Americans, including Brazilians., ${ }^{2,10-12}$

The association of CMD with medically unexplained somatic complaints in primary care strongly contributes to the low detection rate of the condition. As a result, undetected CMD patients go regularly to primary care centers, where complementary exams are excessively requested and they are frequently referred to specialists, or receive inadequate treatment by general practitioners. ${ }^{13,14}$

Another important aspect that has been demonstrated is that a higher prevalence of CMD is associated with socio-economic and demographic factors, such as income, gender, education and marital status. ${ }^{15-22}$ The association between CMD and low income is so frequent that Patel and Kleinmann have suggested they should be considered a disease associated with poverty. ${ }^{19}$ Although the authors consider the possibility of reverse causality in this association, they do not rule out the hypothesis that there could be a vicious circle in which poverty generates CMD that, in turn, generate more poverty and so on, making it even more difficult for these people to overcome unfavorable social situations. Another variable frequently found in association with CMD in these studies is a low education level (mainly illiteracy).

However, Eide et al. demonstrated, many years ago, that social networks act as an interactive factor, reducing the impact of stressful events on the presence of somatic and psychological complaints. ${ }^{23}$ Brugha et al. ${ }^{24,25}$ also confirmed that the density (number of people) of the social support network is inversely associated with the presence of mental disorders. In addition, Patel and Kleinmann suggested that loneliness is a factor associated with CMD, ${ }^{19}$ and Targosz et al. showed an association between depression and not having a partner in women with children. ${ }^{24}$

All surveys conducted in primary care centers have shown that $\mathrm{CMD}$ are more common among women. In fact, women account for more visits to health care centers than men. Moreover, patients with CMD are among those that come more frequently to the centers, usually with medically unexplained complaints. ${ }^{21}$ Women with CMD also are mothers of underweight children (younger than 4 years of age), ${ }^{22}$ therefore, CMD may also be relevant for children's health. Although public health policies consider these children a priority, the fact that their inadequate feeding and caring can be a consequence of the mental suffering of their mothers has not yet been considered for the development of proper interventions.

Taking into consideration the movement "No Health without Mental Health" ${ }^{26,27}$ presented in "Launching a new movement for mental health", by Horton, in The Lancet, it is important to discuss which should be the primary steps to integrate mental health care into primary care and to organize a collaborative care system within the framework of the Brazilian public health system. ${ }^{28}$

One important question about this integration could be: "What are the mental health complaints presented by patients routinely attending primary care and what is being done to help these patients"?

These are patients who usually have CMD. Although, quite frequently, CMD have not been considered a priority both to the FHP and to the Psychiatric Reform.

Our objectives in this article are to demonstrate that CMD are an important public health concern in primary care in Brazil, based on their prevalence and association with demographic and socio-economic variables (including social support networks); to detect whether there is any special group of patients that should be considered to be in greater risk for CMD; and to recommend alternative interventions to aid patients, within the Family Health Strategy, with support from mental health professionals.

\section{Method}

\section{Design and study population}

In 2002, a survey on CMD in primary care ${ }^{6}$ was conducted in five urban centers of the FHP in the Municipality of Petropolis. These centers were selected because they received undergraduate nursing and medical students for training. Petropolis is located in the mountainous region of the State of Rio de Janeiro, and has 300,000 inhabitants distributed in rural and industrialized urban areas. The reference population for the sample was made up of patients attending the FHP centers from August to December 2001, amounting to a total of 4,928 patients. All patients from 18 to 65 years of age, seen by a family doctor were interviewed for a period of 30 days at each center between August and December 2002. Patients younger than 18 years or older than 65 years of age and patients with abnormal cognitive functioning were excluded from the study.

This research was submitted to the consideration of the Committee for Ethics of the Social Medicine Institute, Universidade do Estado do Rio de Janeiro-UERJ (Comitê de Ética do Instituto de Medicina Social/UERJ) and was regarded as adequate for humans in December 2001. 


\section{Measures}

Common mental disorders were evaluated using the Brazilian version of the General Health Questionnaire - 12 items (GHQ12). ${ }^{3,6,29,30}$ Scores for individual items were coded as absent or present ( 0 or 1$)$ and then summed up, and total scores of 3 or higher (out of 12) were classified as CMD cases. The Brazilian version of GHQ-12,3,6,30 at the cutoff point of $2 / 3$, showed sensitivity of $91 \%$ and specificity of $71 \%$, and, at the cutoff point of $4 / 5$, for a population with no more than four years of schooling, showed sensitivity of $76 \%$ and specificity of $82 \%{ }^{3,30}$ As most of the patients had a low level of education, the questionnaires were read to them by the interviewers, as has been previously done in others studies on this subject in Brazil. ${ }^{2-6,30}$

Due to the homogeneity of the population attending the FHP, the relative small size of the sample, and considering the factors already known to be related to CMD, it was decided that the socio-economic factors present in the study should be organized as dichotomous variables. The following variables were studied: gender, level of poverty (monthly per capita income of no more than U\$40), lack of any personal source of income, marital status (not having a partner), age (younger than 45 years of age) and illiteracy. The same strategy was used for the analysis of social support networks: regularly attending church (at least twice a month); participating in sports or artistic activities; participating in political activities or unions; and participating in charity or non-governmental organizations, as well as the size of the social networks, including friends and relatives. Previous studies 5 considered that having at least four people that could be trusted constituted a social support network.

\section{Data analysis}

The primary outcome measure, i.e., common mental disorder according to the GHQ-12, was treated as a dichotomous variable using a cutoff point of 3 . Our main exposure variables were gender, level of poverty (extremely poor), absence of any personal source of income, not having a partner, age (younger than 45), illiteracy and presence of a social support network.

Descriptive data on the sample and frequency distributions of the main outcome and exposure variables are presented. Common mental disorders prevalence ratios for all the main exposure variables were estimated using a generalized linear model (robust Poisson method) before and after adjusting for other variables. Statistical interaction, or effect modification, was assessed quantitatively by formal statistical tests introducing product terms into the regression models. The SPSS 16 was used for data analysis.

\section{Results}

A total of 714 patients were interviewed (93\% of the total number of patients seen by doctors during the period of the study). Patients were mainly women $(74.1 \%)$, married $(60.8 \%)$, catholic $(57.6 \%)$ and $52.1 \%$ declared to be white; $39.5 \%$ of the patients were between 50 and 65 years old, 37.5\% between 34 and 49 and 23\% were between 18 and 33. The level of education of the patients was low: $8.7 \%$ were illiterate, $45.3 \%$ had less than four years of schooling and only $13.8 \%$ had more than 8 years of schooling. $35 \%$ of the patients had a family income level lower than US $\$ 40$ per month, and only $4.4 \%$ had a monthly income higher than US\$120.

Considering the type of visit, $37.4 \%$ came for new consultations, $36.6 \%$ for follow-up sessions and $25.1 \%$ for group treatment, usually for hypertension and diabetes.

As has already been described in a previous paper, ${ }^{6}$ the prevalence of CMD for a GHQ12 cutoff point of 2/3 was $56 \%$ (95\% CI 52.4-59.6). When adjusted by the GHQ specificity and sensitivity, for this cutoff point, the adjusted prevalence was $64 \%$ of CMD. ${ }^{6}$ There was a significant difference $(\mathrm{p}<0.05)$ between the prevalence of CMD in patients attending group treatment (49\%) and patients coming to the FHP with new complaints (62\%).

The bivariate analysis showed a statistically significant positive association between CMD and gender (female), age (younger than 45), marital status (single), level of poverty (per capita family income lower than US $\$ 40$ per month) and lack of personal income. Level of education, considering both the number of years of schooling and illiteracy did not present any statically significant association, neither did race (not Caucasian), nor did the number of dependent family members (Table 1).

After adjusting for confounding variables, there was an important change in the PR of some variables, which led to a stratification of the variable measuring income. Interactions between an extreme level of poverty, gender and illiteracy were found, demonstrating that these factors are correlated (Table 2), and that extremely poor women are more vulnerable to CMD, increasing the prevalence of CMD by $8.8 \%$.

Another interesting result involves the interaction between level of education (illiteracy) and CMD. Although illiteracy does not seem to have an impact on CMD among extremely poor patients, the same is not true for patients who are not that poor. Illiterate patients who are not extremely poor present an increase of $8.5 \%$ in CMD.

With respect to the association between CMD and the presence of a social support network, it was demonstrated that, when both relatives and friends were considered, having a group of more than four trusted relations revealed to be inversely associated with CMD in the bivariate analysis. Other social network-related activities such as going to church and participating in sports and artistic activities showed a protective effect for CMD. These effects persisted following adjustment by confounding variables. However, participation in charitable events, political parties, unions or non-profitable organizations was not statistically significant (Table 1).

\section{Discussion \\ 1. The problem}

As expected, there was a high prevalence of CMD among patients attending FHP centers in the municipality of Petrópolis. Results were similar when compared to those found at traditional 
Table 1 - Unadjusted and adjusted prevalence ratios (PR) of CMD (GHQ-12) according to socioeconomic and demographic characteristics and having social network support, with respective $95 \%$ confidence intervals $(95 \% \mathrm{CI})$, in a sample of patients attended in Family Health Program Centers in Petropolis, Rio de Janeiro, Brazil $(\mathbf{N}=714)$

\begin{tabular}{|c|c|c|c|c|}
\hline Variable & CMD (\%) & p-value & Unadjusted PR (95\%Cl) & Adjusted PR $(95 \% \mathrm{Cl})$ \\
\hline \multicolumn{5}{|l|}{ Gender } \\
\hline Male & $73(39.2)$ & $p<0.000$ & 1.00 & 1.00 \\
\hline \multicolumn{5}{|l|}{ Age ( dichotomous) } \\
\hline From 46 to 65 & $188(47.5)$ & $p=0.033$ & 1.00 & 1.00 \\
\hline From 18 to 45 & $208(52.5)$ & & $1,15(1.01-1.32)$ & $1.165(1.02-1.33)$ \\
\hline \multicolumn{5}{|l|}{ Illiteracy } \\
\hline Not Illiterate & $361(55.4)$ & $p=0.22$ & 1.00 & 1.00 \\
\hline Illiterate & $39(62.9)$ & & $0.14(0.93-1.39)$ & $1.06(0.84-1.33)$ \\
\hline \multicolumn{5}{|l|}{ Marital situation } \\
\hline Having a mate & $221(50.9)$ & $p=0.001$ & 1.00 & 1.00 \\
\hline Not having a mate & $179(63.9)$ & & $1.25(1.10-1.43)$ & $1.23(1.08-1.40)$ \\
\hline \multicolumn{5}{|c|}{ Monthly family per capita income } \\
\hline Less U\$\$40 & $149(61.1)$ & & $1.15(1.01-1.32)$ & $1.08(0.95-1.24)$ \\
\hline \multicolumn{5}{|l|}{ Having personal income } \\
\hline Yes & $283(53.6)$ & $p=0.194$ & 1.00 & 1.00 \\
\hline No & $117(62.9)$ & & $0.99(0.99-1.00)$ & $1.00(0.99-1.00)$ \\
\hline \multicolumn{5}{|l|}{ Family network bigger than 4} \\
\hline No & $353(59.7)$ & $p<0.000$ & 1.00 & 1.00 \\
\hline Yes & $47(39.2)$ & & $0.68(0.55-0.84)$ & $0.69(0.56-0,86)$ \\
\hline \multicolumn{5}{|l|}{ Friends network bigger than 4} \\
\hline No & $367(58.3)$ & $p=0.002$ & 1.00 & 1.00 \\
\hline Yes & $30(38.5)$ & & $0.67(0.53-0,86)$ & $0.69(0.54-0.90)$ \\
\hline \multicolumn{5}{|c|}{ Participation in sports/artistic activities } \\
\hline No & $340(58.5)$ & $p=0.007$ & 1.00 & 1.00 \\
\hline Yes & $60(45.1)$ & & $0.77(0.63-0.94)$ & $0.80(0$ 65-0.98) \\
\hline Yes & $252(53.1)$ & & $0.86(0.75-0.97)$ & $0.84(0.74-0.96)$ \\
\hline \multicolumn{5}{|c|}{ Participation political/syndicate activities } \\
\hline No & $327(57.5)$ & $p=0.142$ & & \\
\hline Yes & $73(50.3)$ & & $1.14(0.96-1.36)$ & \\
\hline \multicolumn{5}{|c|}{ Participation civil societies/charity activities } \\
\hline No & $328(57.4)$ & $p=0.146$ & $1.14(0.95-1.36)$ & \\
\hline Yes & $72(50.3)$ & & & \\
\hline
\end{tabular}

'Adjusted for sex, age, marital situation, illiteracy, personal and family income.

primary care center in studies carried out in Brazil by Mari, Busnello and Iacopponi ${ }^{3-5}$ in the 1980 s and Villano ${ }^{2}$ in the 1990 s. Over $50 \%$ of patients present CMD.

As in other studies, the association between CMD and precarious social and economic conditions was confirmed, particularly for women living in unfavorable social conditions. ${ }^{15,16,18,21,22}$ The interaction between gender and income led to a threefold increase in the risk of CMD in women living in extreme poverty. This is of particular importance when planning public health interventions, especially when it is already known that mothers of undernourished children have a high prevalence of CMD. ${ }^{22}$

As far as the educational level is concerned, this study could not, at first, establish any association with CMD. Upon studying the way in which poverty was stratified, the interaction between illiteracy and CMD was seen only in women who were not extremely poor. It is our interpretation that when extreme poverty is not present, illiteracy is more powerfully associated with CMD. As Patel and Kleinmann pointed out, poverty is associated with CMD by the deleterious effect that extreme poverty brings to selfrespect and self-esteem, as it is often accompanied by experiences and feelings of worthlessness, lack of hope and impotence. ${ }^{19}$ Being illiterate among those who are not extremely poor may also create stigma which, in turn, generates a negative self image and bad feelings.

Social support networks such as having a partner, having more than four trusted relatives or friends, going to church regularly and 
participating in sports and artistic activities, showed a protective effect against CMD. ${ }^{24,25}$ Considering that this is a cross-sectional study, it is not possible to know the direction of the association, although religion has been shown to have a protective effect in the presence or course of mental disorders. The same applies to sporting activities. We can therefore consider that, at FHP centers in Brazil, there is a particular group of CMD patients constituted by poor, illiterate women below 45 years of age without a support network to whom therapeutic alternatives should be provided.

According to previous studies, women with CMD are also among the patients who regularly visit health care centers, ${ }^{2}$ present complaints of several medically unexplained symptoms, ${ }^{10-12}$ and are the mothers of undernourished children. ${ }^{22}$

\section{The existing solutions}

At a primary care level, treatment and support for patients with CMD need to be considered as a mental health priority. The fact that CMD are associated with social and family problems represents a strong reason for the national health care system to introduce strategies to mitigate the suffering of these patients, helping them feel stronger in order to overcome their problems. CMD represent a significant mental health problem in primary care. Low income should not be an impediment for treating CMD and health strategies must include the development of interventions, with a consistent level of scientific evidence as to their efficiency, to assess and treat CMD.

Some interventions are already being implemented in Brazil thanks to the integration of mental health and the family health program strategy. These include the introduction of community support groups such as "Community Therapy" (CT), which has been available in the national health system for several years. ${ }^{31}$

Several international studies have also shown positive evidence for the treatment of common mental disorders in primary care through drugs or psychosocial treatments. In many of these trials, usually conducted in developed countries, interventions were applied by counselors in primary care in an individual basis, ${ }^{32}$ and involved cognitive-behavior and interpersonal or problem solving therapies. Nonetheless, Patel et al. stressed, in a recent narrative review, that there is strong evidence from low and middle income (LAMI) countries of effective options for treating depression with both drugs and psychological treatments. ${ }^{33}$ These trials are from Chile, ${ }^{34}$ India, ${ }^{35}$ Uganda, ${ }^{36}$ Pakistan $^{37}$ and Mexico ${ }^{38}$ and have presented different successful treatments conducted by primary care professionals, either through individual or group interventions.

Moreover, Dowrick ${ }^{39}$ highlighted the role of training primary care professionals, structuring care pathways and organizing an approach involving community mental health centers in order to obtain effective prescriptions and psychosocial treatments in primary care. Therefore, training primary care professionals to assess and manage mental health conditions is essential and should involve additional skills other than simply diagnosing and medicating mental disorders. Therapeutic tools for increasing mental health in primary care must include: developing communication skills; being able to work within a more comprehensive model rather than a biomedical one; coping with severe psychosocial problems; and being able to use active psychosocial interventions, including cognitive-behavior and problem-solving therapy.

One of the most important aspects concerning the treatment of patients with CMD is changing the attitude of doctors and nurses towards mental disorders and their treatment. Studies have demonstrated that the presence of a mental health professional helps primary care workers to deal with patients with mental disorders and their frequent psychosocial problems. ${ }^{40}$

The Family Health Strategy in Brazil, following Alma-Ata proposals, considers that health promotion, disease prevention and social empowerment are important endeavors for health teams. Family Health Strategy teams can assist women with CMD to overcome the vicious circle of poverty and mental disorders as has been done in other countries. ${ }^{34-38}$ Integrating FHP and MH teams is being considered a priority in public health policy for the next years. The Brazilian National Mental Health Policy considers expanding the integration of primary care and mental health professionals a strategic priority and, in order to do so, it created the Núcleos de Apoio à Saúde da Família in 2008. ${ }^{28}$

There are some limitations to this study. The first one relates to the fact that this is a cross-sectional study and so it is not possible to make causal inferences from the results, such as the association between social support and common mental disorders. The second one involves the fact that the General Health Questionnaire, the main tool used to measure outcome, is a screening test for

Table 2 - Crude and Adjusted Prevalence Ratios (with 95\% Cl) for the association between being extremely poor and CMD (GHQ-12), stratified by sex and being illiterate in a sample of patients attended in Family Health Program Centers in Petropolis, Rio de Janeiro, Brazil (N = 714)

\begin{tabular}{lccc}
\hline & Prevalence & Crude PR (95\% Cl) & Interaction \\
\hline Not being extremely poor & & & \\
Illiterate & $71.43(p=0.042)$ & $1.38(1.07-1.78)$ & \\
Female & $56.78(p=0.011)$ & $1.30(1.05-1.60)$ & \\
Being extremely poor & & & \\
Illiterate & $51.61(p=0.25)$ & $0.83(0.58-1.18)$ & $0.60(0.39-0.92)$ \\
Female & $69.35(p<0.000)$ & $2.84(1.68-4.78)$ & $2.19(1.24-3.8)$ \\
\hline
\end{tabular}

* Excluded variables of interation model, because small centers number in sample 
CMD, thus precluding the study of specific mental disorders in primary care. The third refers to the fact that the data comes from a single municipality in the Southeastern region of Brazil, limiting generalization of the results.

\section{Conclusion}

Social inequity is strongly associated with common mental disorders in patients attending primary care centers in the new FHP in Brazil. The results demonstrate that women that are extremely poor are a group of patients under greater risk for CMD. Concerning the reality of the new Brazilian health system, with the introduction of the Family Health Strategy, it is possible to suggest that Brazilian primary care professionals, with the support of mental health teams, can organize a collaborative care system that will make it possible to help CMD patients in the near future.

\section{Acknowledgements}

This study was developed as the PHD thesis in Public Health of Dr. Sandra Fortes. Jair de Jesus Mari and Claudia de Souza Lopes are researchers of the Conselho Nacional de Desenvolvimento Cientifico e Tecnológico (Brazilian Research Council, CNPq).

We are especially grateful for the Faculdade de Medicina de Petrópolis and the Family Health Program (including its doctors and nurses) from the Health Secretary of Petrópolis for their collaboration and support.

Disclosures

\begin{tabular}{|c|c|c|c|c|c|c|c|}
\hline $\begin{array}{l}\text { Writing group } \\
\text { member }\end{array}$ & Employment & $\begin{array}{l}\text { Research } \\
\text { grant }^{1}\end{array}$ & $\begin{array}{l}\text { Other research grant } \\
\text { or medical continuous } \\
\text { education }^{2}\end{array}$ & $\begin{array}{l}\text { Speaker's } \\
\text { honoraria }\end{array}$ & $\begin{array}{l}\text { Ownership } \\
\text { interest }\end{array}$ & $\begin{array}{l}\text { Consultant/ } \\
\text { Advisory } \\
\text { board }\end{array}$ & Other $^{3}$ \\
\hline Sandra Fortes & UERJ & $\begin{array}{c}\text { CNPq } \\
\text { FAPERJ }\end{array}$ & CEPESC & - & - & - & - \\
\hline Claudia S. Lopes & UERJ & - & - & - & - & - & - \\
\hline Luiz A. B. Villano & UERJ & - & - & - & - & - & - \\
\hline Mônica R. Campos & $\begin{array}{l}\text { Public Health } \\
\text { National } \\
\text { School }\end{array}$ & - & - & - & - & - & - \\
\hline Daniel A. Gonçalves & UNIFESP & - & - & - & - & - & - \\
\hline Jair de Jesus Mari & UNIFESP & $\begin{array}{l}\text { CNPq } \\
\text { FAPESP } \\
\text { OMS }\end{array}$ & - & $\begin{array}{c}\text { Eli-Lilly } \\
\text { AstraZeneca } \\
\text { Janssen }\end{array}$ & - & - & - \\
\hline
\end{tabular}

\section{References}

1. Goldberg D, Huxley P. Common mental disorders: a bio-social model. London: Tavistock/Routledge; 1992.

2. Üstun TB, Sartorius N. Mental illness in general health care: an international study. Chichesser, England: John Wiley \& Sons; 1995.

3. Mari JJ. Minor psychiatric morbidity in three primary care clinics in the city of São Paulo. Issues on the mental health of the urban poor. Soc Psychiatry Psychiatr Epidemiol. 1987;22(3):129-38.

4. Iacopponi E. The detection of emotional disorders by primary care physicians: a study in São Paulo, Brazil. Ph.D. thesis, London: University of London; 1989.

5. Busnello ED, Lima B, Gomes R, Bertollote JM. Identificação e manejo dos doentes mentais num local de cuidados primários em Porto Alegre, Brasil. JBP. 1983;32(6):359-63.

6. Fortes S, Villano LAB, Lopes CS. Nosological profile and prevalence of common mental disorders of patients seen at the Family Health Program (FHP) centers in Petrópolis, Rio de Janeiro. Rev Bras Psiquiatr. 2008;30(1):32-7.
7. Lima MCP. Transtornos mentais comuns e uso de álcool na população urbana de Botucatu - SP: um estudo de comorbidade e utilização de serviços. Ph.D thesis, São Paulo Medicine Faculty; 2004.

8. Maragno L, Goldbaum M, Gianini RJ, Novaes HM, César CL. Prevalence of common mental disorders in a population covered by the Family Health program (Qualis) in São Paulo, Brazil. Cad Saude Publica. 2006;22(8):1639-48.

9. Piccinelli M, Rucci P, Üstun B, Simon G. Typologies of anxiety, depression and somatization symptoms among primary care attenders with no formal mental disorders. Psychol Med. 1999;29(3):677-88.

10. Lobo A, Garcia-Campayo J, Campos R, Marcos G, Perez - Echeverria MJ Somatisation in Primary Care in Spain I: Estimates of Prevalence and Clinical Characteristics. Br J Psychiatry. 1996;168(3):344-8.

11. Gureje O, Simon G, Ustun T, Goldberg D. Somatization in cross-cultural perspective: a World Health Organization study in primary care. Am J Psychiatry. 1997;154(7):989-95. 
12. Isaac M, Janca A, Burke KC, Costa e Silva JA, Acuda SW, Altamura AC, Burke JD, Chandrashekar CR, Miranda CT, Tacchini G. Medically unexplained somatic symptoms in different cultures. Psychother Psychosom. 1995;64(2):88-93.

13. Kessler D, Lloyd K, Lewis G, Gray DP. Cross sectional study of symptoms attribution and recognition of depression and anxiety in primary care. BMJ. 1999;318(7181):436-40.

14. Kirmayer LJ, Robbins JM, Dworkind M, Yaffe MJ. Somatization and the recognition of depression and anxiety in primary care. Am J Psychiatry. 1993; 150(5):734-41.

15. Ludermir AB. Inserção produtiva, gênero e saúde mental. Cad Saude Publica. 2000;16(3):647-59

16. Ludemir $A B$, Lewis $G$. Links between social class and common mental disorders in Northeast Brazil. Soc Psychiatry Psychitr Epidemiol. 2001;36(3):101-7.

17. Weich $S$, Lewis $G$, Jenkins $S$. Income inequality and the prevalence of common mental disorders in Britain. BrJ Psychiatry. 2001;178:222-7.

18. Weich S, Sloggett A, Lewis G. Social roles and gender difference in rates of the common mental disorders in Britain: a 7 year, population - based cohort study. Psychol Med. 2001;31(6):1055-64.

19. Patel V, Kleinman A. Poverty and common mental disorders in developing countries. Bull World Health Organ. 2003;81(8):609-15.

20. Araya R, Lewis G, Rojas G, Fritsch. Education and income: which is more important for mental health? J Epidemiol Community Health. 2003;57(7):501-5.

21. Coutinho E, Almeida Filho N, Mari JJ, Rodrigues L. Gender and minor psychiatric morbidity: results of a case-control study in a developing country. Int J Psychiatry Med. 1999;29(2):197-208.

22. Miranda CT, Turecki G, Mari JJ, Andreoli SB, Marcolim MA, Goihman S, Puccini R, Strom B, Berlin J. Mental health of the mothers of malnourished children. Int J Epidemiol. 1996;25(1): 1-6.

23. Eide R, Thyholdt R, Hamre E. Relationship of psychological factors to bodily and psychological complaints in a population in Wessern Norway. Psychoter Psychosom. 1982;37(4):218-34.

24. Targosz S, Bebbington P, Lewis G, Brugha T, Jenkins R, Farrell M, Meltzer H. Lone mothers, social exclusion and depression. Psychol Med. 2003;33(4):715-22. 25. Brugha TS, Morgan Z, Bebbington P, Jenkins R, Lewis G, Farrell M, Meltzer H. Social support networks and types of neurotic symptom among adults in British households. Psychol Med. 2003;33(2):307-18.

26. Horton R. Lauching a new movement for mental health. Lancet. 2007;370(9590):806.

27. Prince M, Patel V, Saxena S, Maj M, Maselko J, Phillips MR, Rahman A. No health without mental health. Lancet. 2007;370(9590):859-77.

28. Brasil. Leis Portaria 154 - 24 de Janeiro de 2008. Criação dos núcleos de apoio à saúde da família. Diário Oficial da União, Brasília (DF). 25 jan. 2008.

29. Goldberg DP, Blackwell B. Psychiatric illness in general practice. A detailed study using a new method of case identification. Br Med J. 1970;1(5707):439-43.

30. Mari JJ, Williams P. A Comparison of the Validity of Two Psychiatric Screening Questionnaires (GHQ-12 and SRQ-20) in Brazil Using Relative Operating Characteristic (ROC) Analysis. Psychol Med. 1985;15(3):651-9.

31. Barreto A. Terapia comunitária: passo a passo. Fortaleza: Gráfica LCR; 2005.

32. Mynors-Wallis L, Gath D, Day A, Baker F. Randomised controlled trial of problem solving treatment, antidepressant medication and combined treatment for major depression in primary care. BMJ. 2000;320(7226):26-30.

33. Patel V, Araya R, Chatterjee S, Chrisholm D, Cohen A, de Silva M, Hosman C, McGuire H, Rojas G, Ommeren M. Treatment and prevention of mental disorders in low-income and middle-income countries. Lancet. 2007;370(9591):991-1005.

34. Araya R, Rojas G, Fritsch R, Gaete J, Rojas M, Simon G, Peters TJ. Treating depression in primary care in low-income women in Santiago, Chile: a randomized controlled trial. Lancet. 2003;361(9362):995-1000.

35. Patel V, Chisholm D, Rabe-Hesketh S, Dias-Saxena F, Andrew G, Mann A. The efficacy and cost-effectiveness of a drug and psychological treatment for common mental disorders in general health care in Goa, India: a randomised controlled trial. Lancet. 2003;361(9351):33-9.

36. Bass J, Neugebauer R, Clougherty KF, Verdeli H, Wickramaratne P, Ndogoni L, Speelman L, Weissman M, Bolton P. Group interpersonal psychotherapy for depression in rural Uganda: 6-month outcomes: randomised controlled trial. $\mathrm{Br}$ J Psychiatry. 2006;188:567-73.
37. Ali BS. Naeem S, Gul A, Mubeen S, Iqbal A. The effectiveness of counseling on anxiety and depression by minimally trained counselors. Am J Psychother. 2003;57(3):324-36.

38. Lara MA, Navarro C, Rubi NA, Mondragon L. Outcome results of two levels of intervention in low-income women with depressive symptoms. $A m J$ Orthopsychiatry. 2003;73(1):35-43.

39. Dowrick C. Advances in psychiatric treatment in primary care. Adv Psychiatric Treatment. 2001;7:1-8.

40. Gask L, Croft J. Methods of working with primary care. Adv Psychiatric Treatment. 2000;6:442-9. 